\section{Positions Available}

\section{POSTDOCTORAL POSITION \\ Plasma Etching for Microelectronics}

The Engineering Research Center for Plasma-Aided Manufacturing at the University of Wisconsin-Madison invites applications for a postdoctoral research position in plasma etching for microelectronics beginning January 1995. Applicants should be experimentalists and have a $\mathrm{PhD}$ degree in a related field and previous experience in plasma processing and etching in particular. Duties of the position include but are not limited to assistance with experimental studies aimed at real-time control of semiconductor etching with advanced high plasma density and low pressure plasma tools (ECR, Inductive, Helicon). Candidates for this position must have excellent verbal and written communication skills and be able to work effectively as part of a team, in the role of a consultant and/or project leader depending on the nature of the various projects. The Engineering Research Center for Plasma-Aided Manufacturing is a crossdisciplinary center funded by the National Science Foundation and a consortium of industrial partners. Applications or nominations should be sent to: Prof. J. Leon Shohet, Director, Engineering Research Center for Plasma-Aided Manufacturing, University of WisconsinMadison, 1410 Johnson Drive, Room 101, Madison, WI 53706-1608.

The University of Wisconsin-Madison is an EO/AA employer.

\section{DEPARTMENT HEAD \\ Materials Engineering Department Rensselaer Polytechnic Institute}

Rensselaer Polytechnic Institute invites nominations and applications for the position of Head, Materials Engineering Department in the School of Engineering. The Department offers $\mathrm{BS}, \mathrm{MS}$, and $\mathrm{PhD}$ programs in most aspects of materials science and engineering including metallurgy, ceramics, glasses, polymers, electronic materials, composites, and processing. The department engages in numerous interdisciplinary activities with other departments and research centers at Rensselaer, and interactions with industry are a priority.

The Department Head is expected to provide leadership in curriculum development and graduate and undergraduate research activities, and should have a broad view of all facets of materials engineering ranging from theoretical and conceptual to applications, design, and manufacturing processes. The Head will be expected to develop and integrate the department's activities in conjunction with other programs on the campus.

Candidates must have an earned doctorate in materials science or engineering or a closely allied field and must be eligible for a tenured professorship in the department. In addition, the candidate should have a record of scholarly achievement and must provide evidence of strong leadership, management and interpersonal skills.

Candidates must supply a curriculum vitae and suitable references to:

Prof. M.E. Glicksman, Chair, Search Committee

Materials Engineering Department

Rensselaer Polytechnic Institute, Troy, NY 12180-3590

glickm@rpi.edu

The deadline for applications is December 31, 1994.

Rensselaer Polytechnic Institute is an Equal Opportunity, Affimative Action Employer. Women and minority candidates are especially encouraged to apply.

\section{POLYMER MATERIALS SCIENTIST/ENGINEER}

W.L. Gore \& Associates, Inc., an innovative company of technologically advanced medical, electronic, fabric, and industrial products, has an exceptional opportunity for a Polymer Materials Scientist or Engineer. We are looking for a technology leader in electromagnetic and polymeric materials. The position, located in the Delaware/Maryland area, requires fundamental and applied property structure understanding of polymers as they interact with electromagnetic radiation.

The successful candidate will be a senior member of the technical team, helping capture significant new market opportunities in signal transmission. This person will be responsible for both new technology development and product development, as well as interaction with both internal and extemal people to apply appropriate unique technologies to new proprietary solutions.

$\mathrm{A} \mathrm{PhD}$ in a related science or engineering field, along with 10 years industrial experience or equivalent, is required. It is very important that this person have a demonstrated history of leadership and of applying technology in a team environment to the creation and commercialization of new products. Superior oral and written communication skills are required.

Please send resume to:

W.L. Gore \& Associates, Inc.

Attn: Sam Kirkland

551 Paper Mill Road, P.O. Box 9206, Newark, DE 19714-9206

An Equal Opportunity Employer.

\section{ASSISTANT PROFESSOR MATERIALS ENGINEERING}

NEW MEXICO INSTITUTE OF MINING AND TECHNOLOGY invites applications from qualified individuals for a tenure-track faculty position in materials science and engineering. We would like to fill the position by January 1995 but will also consider applications for August 1995. Appointment is expected to be at the assistant professor level, but appointment at the associate professor level will be considered. The position entails teaching undergraduate and graduate level courses in materials science and engineering, active involvement in research and providing service to the Institute. Applicants must possess a PhD in materials science and engineering or a related materials field. Applicants should have research experience in metalorganic chemical vapor deposition and transmission electron microscopy and knowledge in $\mathbf{x}$-ray diffraction, solid-state diffusion, and optical materials. Applicants should be able to provide evidence of excellence in teaching, appropriate research, publications and service, and must be able to demonstrate good oral and written communication skills in English. Applicants should include a cover letter, curriculum vitae, graduate transcripts, three letters of reference and a brief description of research interests. Address applications to: New Mexico Institute of Mining and Technology, Human Resources, Wells Hall Box C-078C, Socorro, NM 87801.

\section{AAEOE}

AD GIOSING DEADLINES

November 1, 1994 for the December Issue December 1, 1994 for the
January 1995 Issue CAIl MARY E. KAUFOID TODAY!

(412) $367-3036$ 
Positions Available

\title{
MATERIALS SCIENTIST
}

Duties: Research properties of silicon for use in silicon substrates. Study crystal growth, surface and intrinsic properties, and wafer processing, including epitaxial deposition and wafer cleaning, to define optimal techniques of fabricating epitaxial and polished wafers. Liaison with outside research groups. Apply research to design and production of silicon substrates to meet customer requirements. Prepare reports and scientific papers about research.

Requirements: PhD degree in materials science or applied physics. Three years' work experience validated by successful completion of at least three research projects in the field of silicon wafer fabrication and deposition of materials, reports of which were published in peer-reviewed scientific journals, or by equivalent recognition. Ability to perform all job duties.

Salary: $\$ 46,093 /$ year

Full time position: 40 hours/week

Location: Salem, Oregon

DIRECT RESUMES AND REFERENCES TO:

Job Order No. 5550776

Oregon State Employment Division, Department of Human Resources

875 Union Street, N.E., Room 201, Salem, OR 97311

\section{Positions Wanted}

The following advertisements are from MRS members seeking employment in materials research and development.

PROSPECTIVE EMPLOYERS-To correspond confidentially with the applicant,

REPLY TO THE APPROPRIATE BOX NUMBER, AS FOLLOWS:

Box No.

c/o MRS Bulletin, Materials Research Society, 9800 McKnight Road, Pittsburgh, PA 15237-6006

PhD seeks industrial/research position in materials science/metallurgical engineering. Two years of teaching/research experience. Also experienced in oxidation of metals, ion implantation and ion beam processing, thin film deposition, UHV techniques, microstructural analysis (TEM, SEM, AES, XRD, RBS). Ten plus joumal publications. Eight plus proceedings papers and presentations. Employers-Please reply to Box XIX, 1001.

PhD (1982) In solid-state physics seeks research position. Author and owner of package for $a b$ initio study of the electron structure, chemical binding, electron and lattice properties of complex solids on the bases of the density functional theory and multiple scattering theory. Extensive experience in the package applying to intermetallics and high $T_{c}$ superconductors. Employers-Please reply to BoX XIX, 1003.
Nanotribologist seeks visiting scholar position. Currently associate professor, leader of nanotribology research group, and PhD student in Laboratory of Solid Lubrication, Chinese Academy of Sciences. Fields of interest are ultrathin film lubrication, nanotribology, or others on tribology. Employers-Please reply to Box XIX, 1004.

Materials Scientist (PhD expected-1994) seeks industrial or national lab/academic position. Eight years industrial/national lab experience in optical characterization of materials including nanocrystalline silicon, fullerene thin films, nonlinear optical materials, and thin magnetic films. Extensive experience (including development) with high power and ultrafast laser systems for materials characterization including femtosecond, continuum spectroscopy. U.S. citizen; DOE Q-clearance. Employers-Please reply to BoX XIX, 1002

\section{Services Available}

TRANSLATION of journal articles, patents, reports, manuals, etc. from German and French into English by experienced materials specialist. Outstanding quality, fast turnaround, competitive rates. For more information call Nicholas Hartmann (708) 524-1191 or fax (708) 524-1355.

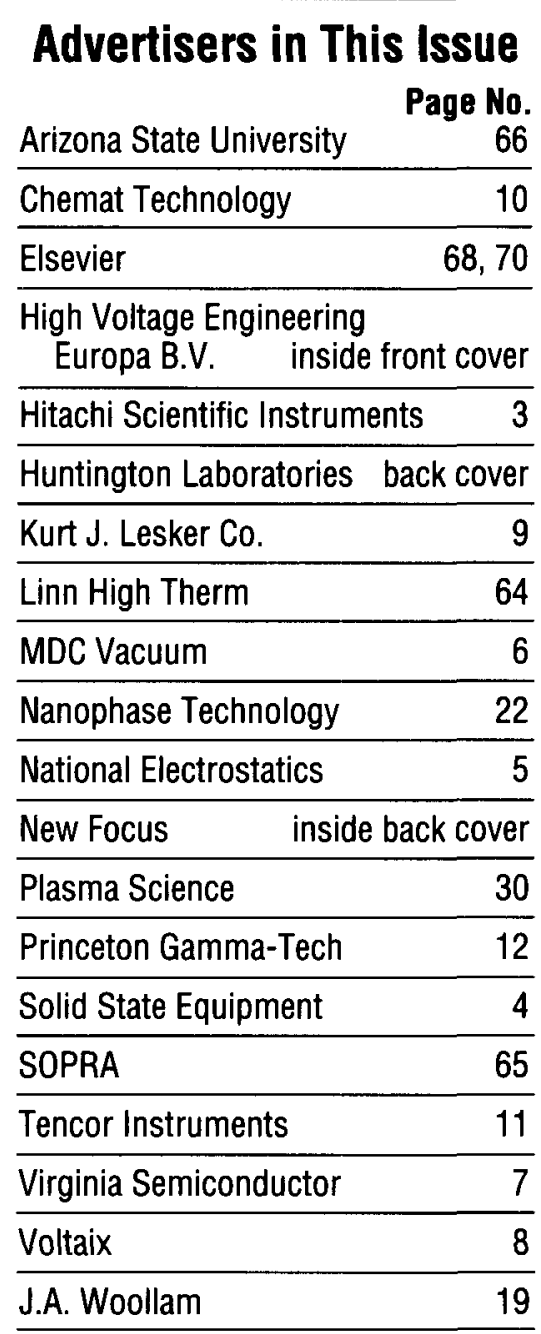

For free information about the products and services offered in this issue, fill out and mail the Reader Service Card, or FAX it to (312) $922-3165$

\section{Job Placement Center at the 1994 MRS Fall Meeting Tuesday, November 29 - Thursday, December 1, 1994}

\author{
Organized and operated by the American Institute of Physics
}

